\title{
The Balcony Spill Plume-Some CFD Simulations
}

\author{
S. MILES, S. KUMAR and G. COX* \\ Fire Research Station, Building Research Establishment \\ Garston, Watford, Herts WD2 7JR, UK \\ *author for correspondence
}

\begin{abstract}
A CFD study is reported which attempts to shed light on the problem of estimating air entrainment into buoyant balcony "spill plumes". This topic has been of some controversy for several years but is of substantial practical importance to the design of smoke control systems in atria and other multi-level complexes. The study described here concerns numerical simulation of the reduced scale physical model from which much of the semi-empirical formulae have been derived. Excellent agreement between measured and predicted mass fluxes are demonstrated in the regions of lower heights of plume rise, but the two apparently diverge at greater heights of rise. Two possible explanations involve the apparently unrealistic assumption of a horizontal smoke layer surface and the validity of the turbulence modelling of this flow. The study does support recent dimensional analyses which suggest only a small degree of air entrainment into the turning region of the smoke flow from the horizontal to the vertical .
\end{abstract}

KEYWORDS: CFD, field models, turbulence modelling, plumes, smoke control

\section{INTRODUCTION}

The current guidance available to practitioners designing smoke control systems for large volumes, such as atria and multi-level shopping complexes, is not without controversy [e.g. 1-3]. The differences of opinion concern primarily how to estimate the air entrainment into the plume of buoyant gases that spill underneath a balcony edge and rise into the large atrium void. Genuine scientific differences have tended to be convoluted with the perceived opposing influences of safety and cost effective design. The practitioner therefore has guidance material that differs both within a particular country (e.g. in the UK references [4] and [5]) and between countries (the NFPA guide [6])). This unsatisfactory position needs to be resolved to enable acceptable fire safety engineering guidance to be developed within ISO and within national standards bodies. Several initiatives are underway to establish a consensus, including reappraisals of existing model scale data $[7,8]$, new helium model studies [9] and, as described here, numerical simulations.

Most of the experimental data which have been used to develop the semi-empirical treatments used for such estimates are from the one-tenth scale physical models of 
Morgan, Marshall and their co-workers [e.g. 1, 10]. It has been how these data have been analysed, and how valid and general are the derived correlations, that has been the subject of debate for several years. Although Yokoi [11] had conducted similar studies earlier he had concentrated on the plumes emitting from relatively narrow vertical openings. Here the concern is with wider openings such as may exist at a shop front.

The current paper seeks to provide further information and insight, based upon the application of CFD, to the problem to help resolve the differences of opinion and interpretation. It describes the application of the JASMINE model [e.g. 12], for which there is a substantial pedigree of validation [see, for example 12-14], to the reduced scale physical model and compares predictions with measurements and correlations derived from dimensional analysis. Although JASMINE does incorporate sophisticated sub-models for the treatment of combustion and thermal radiation [13] these have not been exploited in the current study. The current study is only of the fluid mechanics. The problem considered is that of the tenth scale physical model which uses either electrical heaters or a small ethanol pool fire within the compartment of fire origin to establish a buoyant plume flowing under the balcony.

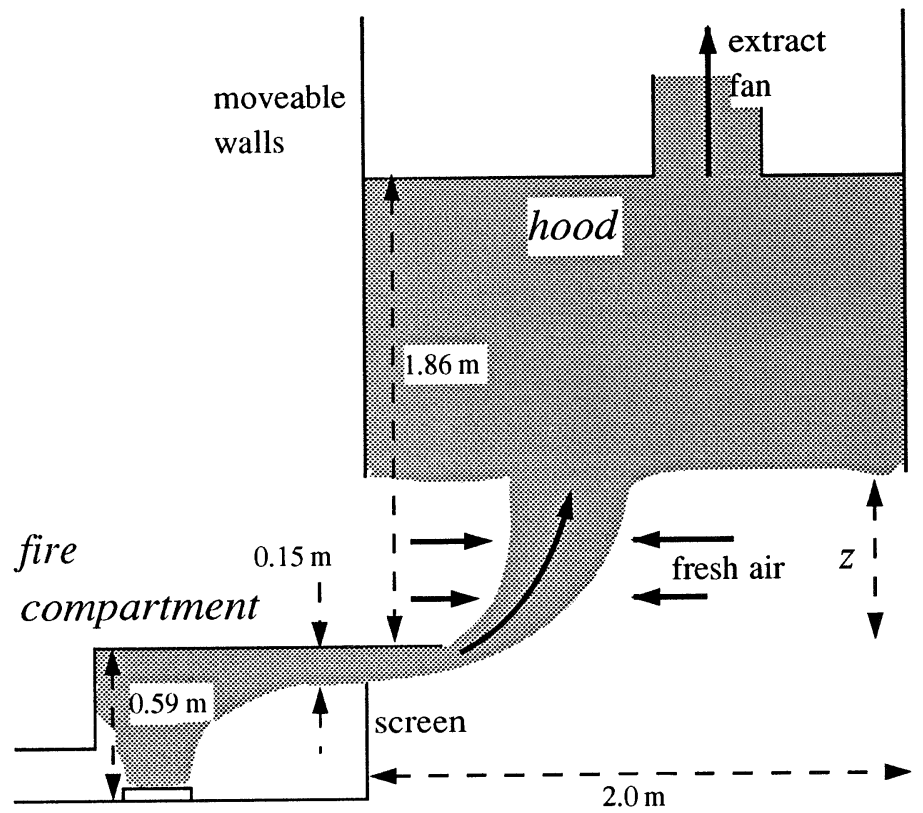

FIGURE 1 Experimental apparatus-larger hood

\section{THE EXPERIMENTAL ARRANGEMENT CONSIDERED}

The experimental apparatus studied here (Figure 1), and described in detail by Marshall and Harrison [10], exploits a similar technique to that used by Zukoski and co-workers [16] to measure entrainment into unbounded fire plumes. A deep hood, containing an adjustable extract fan at its top, collects the heated gases emerging from a "fire compartment" opening into it. The fan is adjusted to maintain the heated gas layer at the bottom of the hood. Entrainment as a function of height of rise is 
measured by raising and lowering the front and back walls of the hood. This entrainment is deduced from the dilution of $\mathrm{CO}_{2}$ generated by the fire source and measured in the extract duct downstream from the fan.

The fire is produced by igniting ethanol in a tilted $0.25 \mathrm{~m}$ square pan. The fuel feed rate, and therefore surface area, were controlled and monitored to supply various levels of heat release rate. A particular feature of these experiments was the use of a sliding vertical screen below the hot gas layer under the compartment ceiling to define the depth of hot gases approaching the balcony edge and to discourage air entrainment from the front of the fire compartment. Instead air was admitted from the back through a low level duct in which the mass flux could be measured.

The dimensions of the fire compartment are $1.0 \mathrm{~m}$ by $0.91 \mathrm{~m}$ in plan and $0.59 \mathrm{~m}$ high. One of the $0.91 \mathrm{~m}$ by $0.59 \mathrm{~m}$ faces is open with the sliding screen defining an adjustable front wall whilst the other is sealed except for a $0.2 \mathrm{~m}$ diameter air inlet duct at low level Two hoods have been studied, $0.91 \mathrm{~m}$ by $2.0 \mathrm{~m}$ and 0.91 by $1.0 \mathrm{~m}$ in plan and with moveable front and back walls to match the height of plume rise being studied. At right angles to the ceiling flow the hood sides come down to balcony level. The tops of the hoods are respectively $1.86 \mathrm{~m}$ and $1.0 \mathrm{~m}$ above the ceiling of the fire compartment. The ceiling of the fire compartment extends a distance of $0.26 \mathrm{~m}$ into the larger, $0.15 \mathrm{~m}$ into the smaller hood to represent the lower surface of a balcony. In the experiments studied here the screen was set $0.15 \mathrm{~m}$ below the compartment ceiling. Each assembly is constructed from ceramic fibre insulation board on a steel frame.

Gas velocities and temperatures were measured in the approach flow and these were used as boundary conditions for the numerical simulations (see Fig 2). In addition gas temperatures inside the hood were measured on thermocouple columns situated on one of its sides.
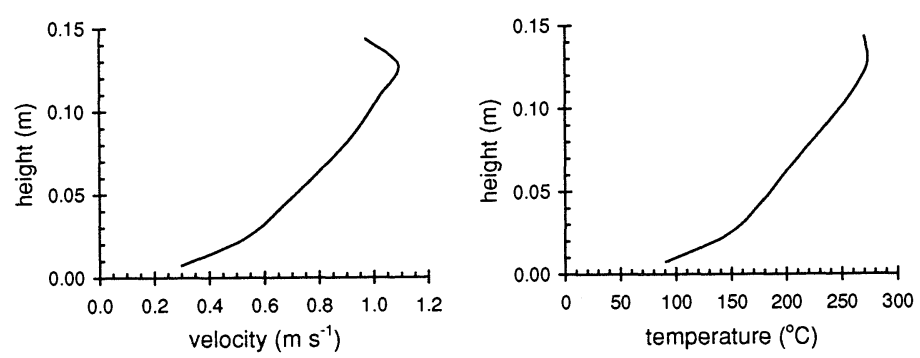

FIGURE 2 Approach flow boundary conditions

In scaled terms these experiments are intended to simulate fires for situations of practical concern. The fire compartment is representative of a full scale compartment, $5.9 \mathrm{~m}$ high containing a fire of several megawatts (between 1.9 to $9 \mathrm{MW}$ in the experiments considered here) opening onto an atrium whose ceiling is between $10 \mathrm{~m}$ and $18.6 \mathrm{~m}$ above the balcony.

\section{NUMERICAL SIMULATIONS}

Only steady state numerical simulations have been performed with the measured mass and heat flux per unit height profiles at the compartment exit plane used as inlet 
boundary conditions for the numerical simulations. No combustion model was exploited and so the fluid was assumed to be heated air only. Local specific heats are deduced from local air temperatures.

Each CFD simulation for a given heat release rate and height of rise was performed according to the following steps which were an attempt to mimic the experiment:

- $\quad$ The geometry was specified with the fire compartment blocked in. Only half the apparatus was modelled, making use of an assumed vertical symmetry plane through the centre of the fire source and midway along the balcony.

- The front/rear walls of the hood were defined such that the clear air gap was $20 \mathrm{~mm}$ less than the experimental visual height of rise $z_{\text {exp }}$.

- A Cartesian grid was applied to the computational domain (the apparatus and free space surrounding it).

- The measured mass and heat flux profiles were prescribed at the exit of the fire compartment.

- The mass extraction rate in the hood exit duct, $\dot{m}_{c f d}$, was set initially to the measured value $\left(\dot{m}_{\exp }\right)$.

- A converged, steady-state solution was obtained.

- The location of the predicted height of rise, $z_{c f d}$, was determined.

- $\quad$ Since in general this was not identical to the experimental value, $\dot{m}_{c f d}$ was then adjusted by $3 \%$ increments/decrements until $z_{c f d}$ equalled the experimental (visual) value $z_{\exp }$ with a converged, steady-state solution obtained after each adjustment.

The difference between $\dot{m}_{c f d}$ and $\dot{m}_{\text {exp }}$ was taken as the main measure of the difference between the CFD solution and the experimental result.

To define the problem properly, fixed-pressure (open) boundary conditions were imposed at the limits of the computational domain, set some distance away from the apparatus; $2.5 \mathrm{~m}$ above the top of the hood, and $2.5 \mathrm{~m}$ and $1.5 \mathrm{~m}$ beyond the hood sides in the direction of the ceiling flow and the balcony width respectively. These boundary conditions were imposed at all domain limits except at the bottom (floor) and the symmetry plane.

Since JASMINE is primarily a Cartesian model, exploiting first order upwind differencing, a relatively fine grid was used in an attempt to eliminate numerical errors in that part of the calculation domain where the flow crosses the numerical mesh obliquely-the worst case for the problem of false diffusion. For the lager hood a total of 168,084 nodes were used; 69 in the vertical direction, 84 horizontally in the direction of the ceiling flow and 29 across the width of the balcony. Of these 53,760 occupied the central volume encompassing the hood and balcony region. A total of 105,336 nodes were used for the smaller hood with the mesh spacing in the turning region of the flow for both cases set at $15 \mathrm{~mm}$. The initial simulation at each height involved 2,500 sweeps of the domain with a further 500 sweeps employed after each adjustment of the extraction fan. This resulted in each solution reported here achieving at least $99.5 \%$ mass balance and $97 \%$ heat balance. 


\section{DIMENSIONAL ANALYSIS}

Since the plume emanating from a wide opening and rising through the atrium volume is approximately two dimensional, the original Morgan and Marshall [1] analysis exploited the weak line plume theory of Lee and Emmons [17] to describe the degree of air entrainment into it. This plume was assumed to emanate from a virtual source at balcony level which absorbed all the properties of air entrainment into the region between the horizontal, under-ceiling, layer and the vertical plume. Their analysis thus assumes self-similar vertical flow with a constant entrainment coefficient of 0.16 and Gaussian lateral velocity and temperature profiles. For this approach to fit their data they had to assume a very high degree of air entrainment in the turning region of the plume.

Recently both Thomas et al [7] and Poreh et al [8] have revisited all the experimental data obtained in the tenth scale model. Thomas et al used dimensional analysis without resort to the assumptions of similarity or constant entrainment coefficient. From this they deduced, rather than assumed, an entrainment coefficient of 0.11 for the larger hood, consistent with more recent studies of line plumes [18, 19]. Furthermore their analysis implied a smaller degree of air entrainment in the turning region. These latest results are presented in the form of the following correlation:

$$
\frac{\dot{m}^{\prime}}{\dot{Q}^{\prime}}=1.2 \frac{\dot{m}_{b}^{\prime}}{\dot{Q}^{\prime}}+0.16 \frac{z}{\dot{Q}^{\prime 2 / 3}}+0.0027
$$

Poreh et al [8], who assumed linearity, reported their results in a form which includes a virtual origin conveniently located at the base of the hot gas layer, viz. [7]:

$$
\frac{\dot{m}^{\prime}-\dot{m}_{b}^{\prime}}{\dot{Q}^{\prime}}=0.15\left(\frac{z+z_{0}}{\dot{Q}^{2 / 3}}\right)
$$

It is important to note that both the above correlations apply only to the larger hood. For the smaller hood, the slope suggested by the data was significantly steeper, around 0.25 [7], but questions remain concerning the veracity of these data, see below. The results from the numerical study described here are compared both with the correlations above and with the specific experimental data points for the cases studied in both larger and smaller hoods.

\section{RESULTS}

Predicted mass flow rates are plotted in Figure $3 a$ in the form suggested by a line plume approximation, viz. $\frac{\dot{m}^{\prime}-\dot{m}_{b}^{\prime}}{\dot{Q}^{\prime / 3}}$ vs. $z$, for both hoods with various heat release rates and heights of rise. The intercept on the vertical axis is a measure of entrainment into the turning region. According to the experimental linear correlations for the larger hood these intercepts are weakly $\dot{Q}^{\prime}$ dependent and slightly different in equations (1) and (2). The two broken lines on Fig 3a represent equation (1) for the extremes of $\dot{Q}$ used in the experiments in the larger hood and equal to $6 \mathrm{~kW}$ and $28 \mathrm{~kW}$.

The numerical simulations suggest a small but finite degree of air entrainment into the turning region identical in both hoods, as would be expected, and close to the lower end of the range suggested by the linear correlations. For the larger hood, the numerical results lie close to the correlation lines, and indeed the experimental data in 
the lower region of the flow, but are clearly not linear, apparently diverging at greater heights of rise. This behaviour was robust to numerical grid refinement (ranging from a total of 15,708 nodes to 168,084$)$. The numerical predictions of $\frac{\dot{m}^{\prime}-\dot{m}_{b}^{\prime}}{\dot{Q}^{\prime / 3}}$ at each height of rise for each $\dot{Q}^{\prime}$ are virtually indistinguishable from each other.

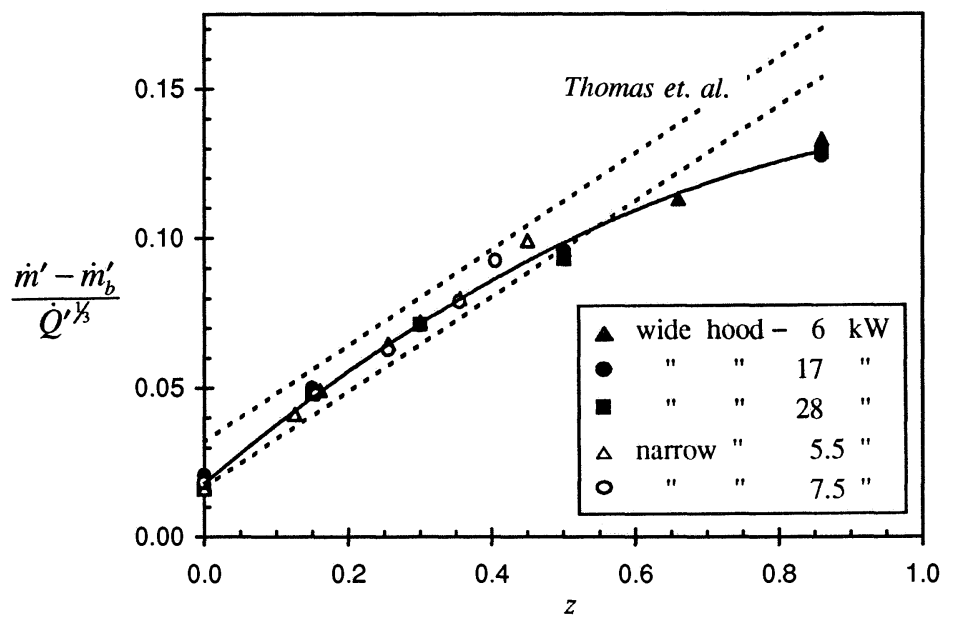

(a)

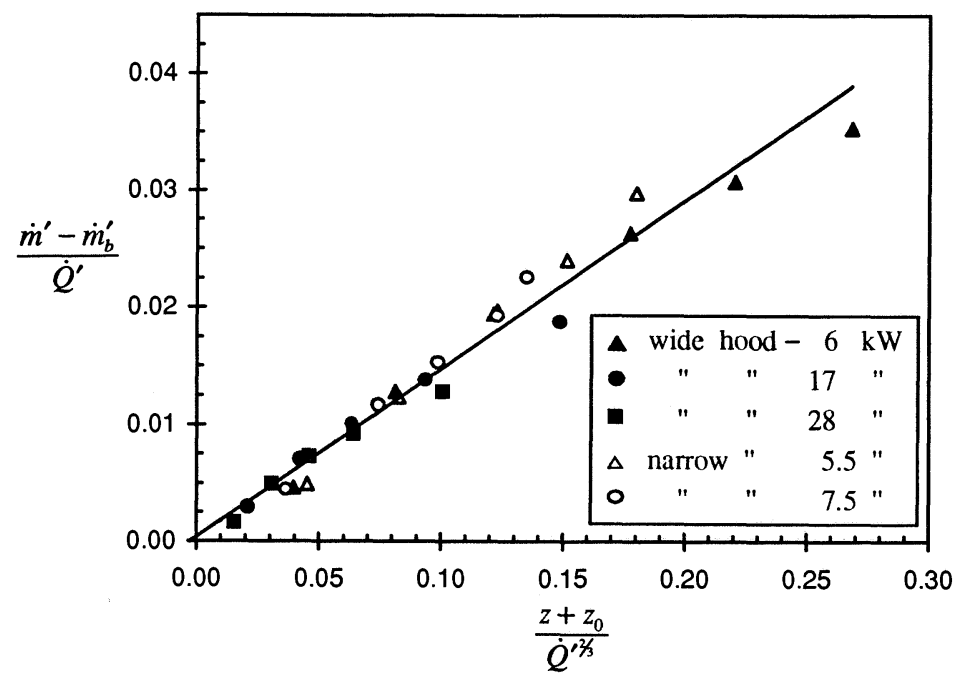

(b)

FIGURE 3 Predicted reduced mass flow rates with (a) height and with (b) reduced height 
For the smaller hood, the numerical predictions are close but not identical to those for the larger hood with apparently a lesser tendency to curvature.

The same numerical data are now re-plotted in Fig $3 \mathrm{~b}$ in the form suggested by the dimensional analysis and in particular equation 2 with the assumption of a virtual origin at $z_{0}=0.15 \mathrm{~m}$, below the compartment ceiling at the 'prescribed,' in the experiments, depth of the hot gas layer used .

A linear correlation through all the numerical data for both hoods gives the following equation:

$$
\frac{\dot{m}^{\prime}-\dot{m}_{b}^{\prime}}{\dot{Q}^{\prime}}=0.14\left(\frac{z+z_{0}}{\dot{Q}^{\prime 2 / 3}}\right)+0.0004
$$

if the line is forced through the origin this becomes:

$$
\frac{\dot{m}^{\prime}-\dot{m}_{b}^{\prime}}{\dot{Q}^{\prime}}=0.15\left(\frac{z+z_{0}}{\dot{Q}^{2 / 3}}\right)
$$

identical to the correlation of Poreh et al [8].

Comparison between predictions and experimental data plotted in the same form are given in Figs 4a and 4b. Clearly the agreement for the smaller hood is much poorer than for the large. However some words of caution are necessary concerning the experimental data for the smaller hood. This data set show a much greater degree of scatter than for the larger hood data and surprisingly do not repeat the similar large hood data at low heights of rise as it presumably should. We will not dwell on these data further.

Ignoring the problems with the small hood data, why are there differences between prediction and measurement at greater heights of rise in the larger hood? The explanation may be associated with the assumption of a single value to describe height of plume rise. The simulations suggest that the bottom of the smoke layer is not always horizontal, as assumed in the experimental study, and that the depth of the layer on one side of the plume may differ from that on the other face with this difference increasing with height of rise. This observation, see Fig 5 for the larger hood, suggests that for the supposedly fixed $0.86 \mathrm{~m}$ height of rise, a more appropriate value would be $0.7 \mathrm{~m}$ on the upper side of the plume and $0.9 \mathrm{~m}$ on the lower, bringing the measured mass flux more in line with the physical correlation.

Another interpretation may be that the turbulence model used in the numerical simulations is failing to predict entrainment accurately. However, previous experience has shown that it has performed well for axisymmetric systems [e.g. 13, 14] albeit studied within compartments where the complex interactions of plume with layer may have obscured any problems associated with plume entrainment rates. It could be that the problem is associated only with two dimensional flows or perhaps it is due to the application of a high Reynold's number turbulence model to a low Reynold's number flow (less than 8000). If so, of course, this would also be a problem for the applicability of this physical scale modelling to the full scale. These are issues that must be addressed in future studies. 


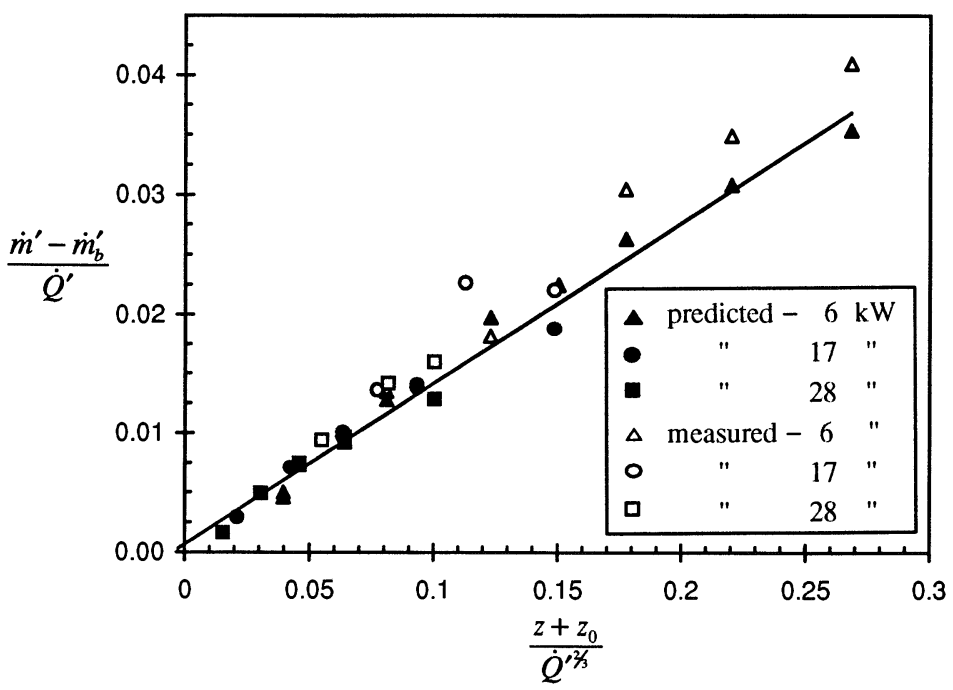

(a) large hood

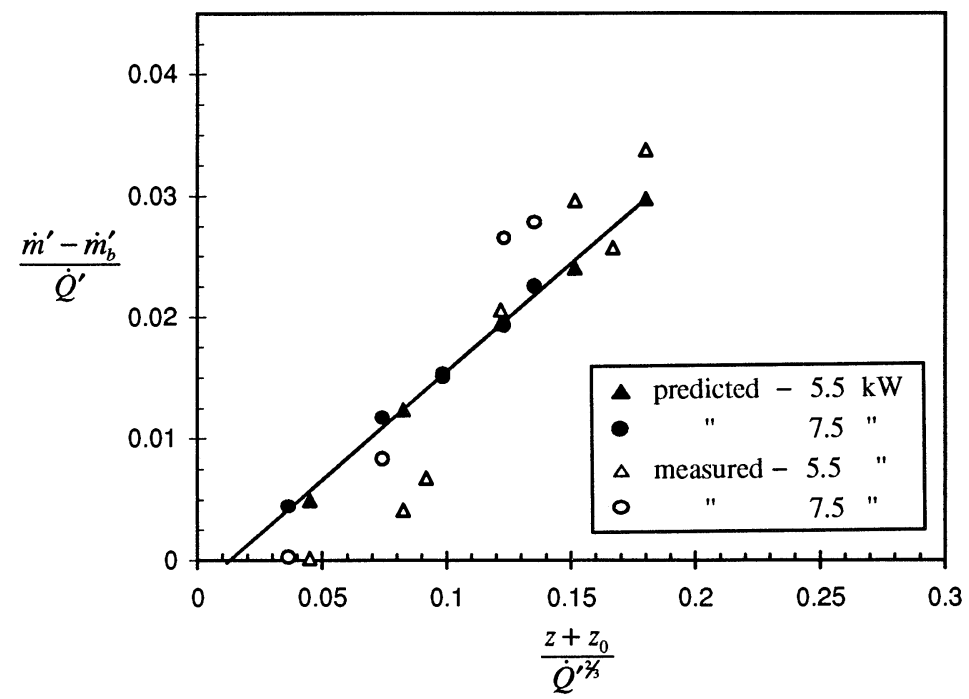

(b) small hood

FIGURE 4 Comparison of predicted and measured mass flow rates for both hoods

From a qualitative viewpoint the simulations show the strong asymmetry in air entrainment at low heights of rise evident in the experiment (Fig. 6a). Much larger local velocities are induced into the upper face of the plume due to the narrow constriction caused by the proximity of the base of the hood to the balcony surface. 
But when the hood is lowered to balcony level this inflow stops and the plume becomes "one-sided" adhering to the inner surface of the hood (Fig 6b). In this configuration even if the fan extraction rate were to reduce, causing the layer to rise, the plume would still remain attached since in the experimental arrangement air inflow from the sides (orthogonal to the primary flow) is denied. In a practical situation, of course, air could enter the upper face from either end. Because of this discontinuity in the top-side entrainment it is perhaps not surprising that the entrainment rate appears non-linear.

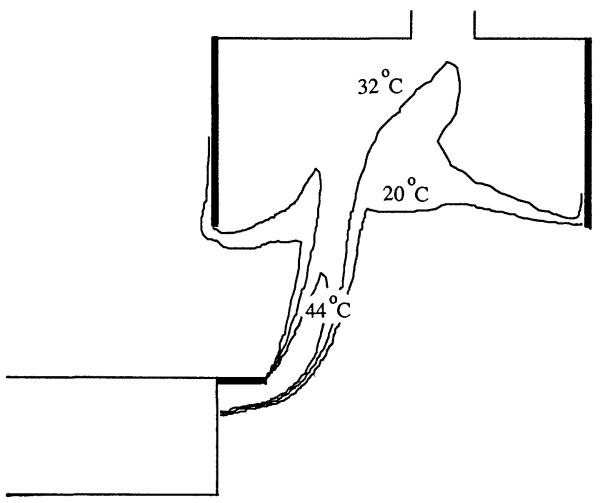

FIGURE 5 Predicted temperature contours at $0.86 \mathrm{~m}$ height of rise in the larger hood $(6 \mathrm{~kW})$

\section{CONCLUSIONS}

This new CFD study has shed some light on the process of air entrainment into the buoyant balcony spill plumes produced in a one-tenth scale physical model. The simulations suggest, contrary to early advice for practitioners [1], only a small degree of air entrainment into the "turning" region of the plume. They agree well, however, with more recent experimental data [10] and the correlations of Thomas et al [7] for low heights of plume rise (less than $0.5 \mathrm{~m}$ at model scale) but seem to diverge at greater heights of rise. It is suggested that this divergence is likely to be due to differing entraining heights on upper and lower surfaces of the plume (Fig 4). However problems associated with the application of the turbulence model to this low Reynold's number, essentially two dimensional, problem cannot be excluded and further detailed comparisons between experimental and numerical studies are essential. The simulations agree well with the correlation of Poreh et al [8] who used the simplifying assumption of a virtual origin at the base of the hot smoke layer in the compartment.

An important issue in the use of the data from these scale models and their utility in predicting real scale behaviour must be the substantially different behaviours between "small" and "large" hoods. Since CFD is perfectly general, it should be capable of predicting behaviour in any situation. The results support this assertion although unresolved differences do remain between the predictions and measurements in the smaller hood. These differences need to be resolved by more joint studies so that practical design can be put on a more firm foundation. 


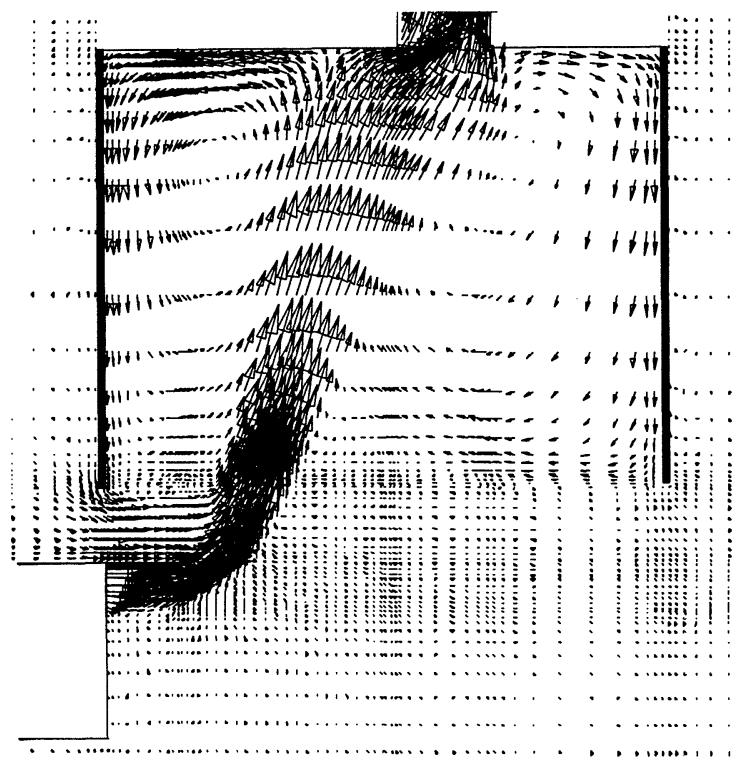

(a) $0.3 \mathrm{~m}$ height of rise

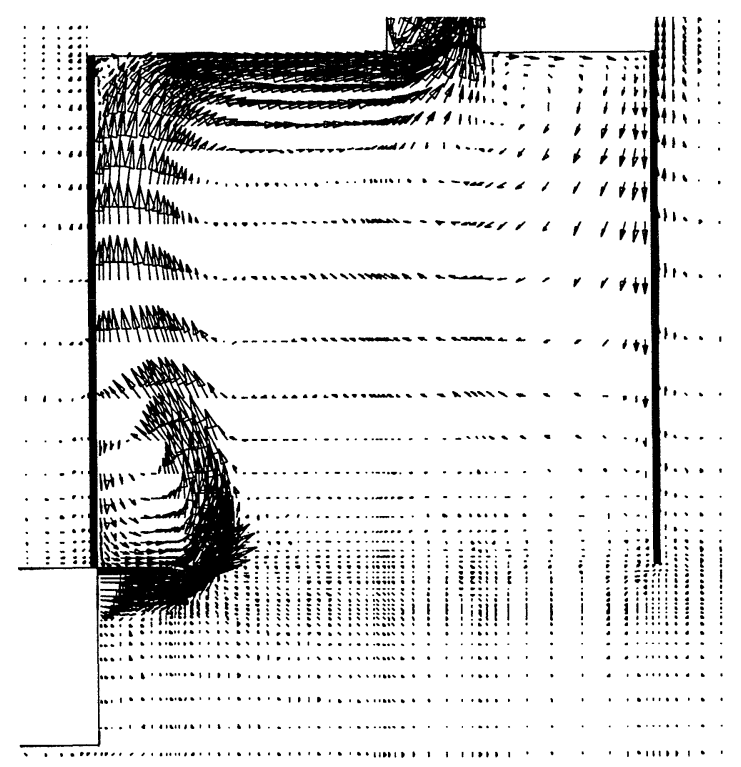

(b) zero height of rise

FIGURE 6 Predicted flow in the larger hood 


\section{ACKNOWLEDGEMENT}

This paper is Crown Copyright 1996 and forms part of the work of the Fire Research Station, Building Research Establishment, Department of the Environment, UK. It is contributed by permission of the Chief Executive of the Building Research Establishment.

\section{REFERENCES}

1. Morgan H. P. and Marshall N. R., Smoke Hazards in Covered, Multi-level Shopping Malls: an Experimentally Based Theory for Smoke Production, BRE CP48/75, Building Research Establishment, 1975

2. Law M., A Note on Smoke Plumes from Fires in Multi-level Shopping Malls, Fire Safety Journal, 10, 197-202, 1986

3. Thomas P.H., On the Upward Movement of Smoke and Related Shopping Mall Problems, Fire Safety Journal, 12, 191-203, 1987

4. Hansell G.O., and Morgan H. P., Design Approaches for Smoke Control in Atrium Buildings, BRE Report BR 258, Building Research Establishment, 1994

5. Relationships for Smoke Control Calculations, CIBSE TM19:1995, Chartered Institute of Building Services Engineers, London, 1995

6. Smoke Management Systems in Malls, Atria, and Large Areas, NFPA 92B, National Fire Protection Association, Quincy, 1991

7. Thomas P.H., Morgan H. P., and Marshall N. R. The Spill Plume in Smoke Control Design, to be published in Fire Safety Journal 1997

8. Poreh M, Morgan H. P., Marshall N. R., and Harrison R., Entrainment by twodimensional spill plumes in malls and atria, to be published in Fire Safety Journal 1997

9. Poreh M, Marshall N. R., Harrison R., and Morgan H.P., A Study of Entrainment by Smoke Plumes in Malls, 1996, private communication Marshall N. R. and Harrison R., Experimental Studies of Thermal Spill Plumes, Building Research Establishment Occasional Paper, OP1, 1996

11. Yokoi S, Study on the Prevention of Fire Spread by Hot Upward Current, Report No. 34, Building Research Institute, Japan, 1960

12. Cox G., and Kumar S., Field Modelling of Fire in Forced Ventilated Enclosures, Combustion Science and Technology, 52, 7-23, 1987

13. Cox G., Kumar S., and Markatos N. C., Some Field Model Validation Studies, Proc First International Symposium on Fire Safety Science, pp159-171, Hemisphere, 1986

14. Kumar S, Gupta A. K., and Cox G., Effect of Thermal Radiation on the Fluid Dynamics of Compartment Fires, Proc Third International Symposium on Fre Safety Science, pp345-354, Elsevier, 1991

15. Kumar S., and Yehia M., Mathematical Modelling of Transient Ceiling Jet Characteristics in Fires, pp 771-777, Proc First Joint ISHMT-ASME Heat and Mass Transfer Conference, Bombay, India 1994

16. Zukoski E. E., Kubota T. and Cetegen B., Entrainment in Fire Plumes, Fire Safety Journal, 3,107-121, 1980/1981

17. Lee S. L., and Emmons H.W., A Study of Natural Convection above a Line Fire, J. Fluid Mechs. 11, 353-368, 1961

18. Ramprian B. R., and Chandrasekhara M. S., Measurements in Vertical Plane Turbulent Plumes, Journal of Fluids Engineering, 111,69-77, 1989

19. Yuan L-M., and Cox G., An Experimental Study of Some Line Fires, Fire Safety Journal, to be published in Fire Safety Journal, 1996 
